\title{
Analytical Study on Seismic Response Reduction for PC Bridge: Effects of Cost on a Proposed Seismic Reinforcement Method Due to Collision
}

\author{
Tomohisa Hamamoto ${ }^{1, ~ *}$, Toshitaka Yamao $^{2}$, Desy Setyowulan ${ }^{3}$ \\ ${ }^{1}$ Department of Civil Engineering, Nishinippon Institute of Technology, Fukuoka, Japan \\ ${ }^{2}$ Center for Water Cycle, Marine Environment and Disaster Management, Kumamoto University, Kumamoto, Japan \\ ${ }^{3}$ Department of Civil Engineering, Universitas Brawijaya, East Java, Indonesia
}

Email address:

hamamoto@nishitech.ac.jp (T. Hamamoto), tyamao@kumamoto-u.ac.jp (T. Yamao), desy_wulan@ub.ac.id (D. Setyowulan)

${ }^{*}$ Corresponding author

\section{To cite this article:}

Tomohisa Hamamoto, Toshitaka Yamao, Desy Setyowulan. Analytical Study on Seismic Response Reduction for PC Bridge: Effects of Cost on a Proposed Seismic Reinforcement Method Due to Collision. Journal of Civil, Construction and Environmental Engineering.

Vol. 5, No. 3, 2020, pp. 42-51. doi: 10.11648/j.jccee.20200503.12

Received: June 2, 2020; Accepted: June 22, 2020; Published: July 7, 2020

\begin{abstract}
After the 1995 Kobe strong earthquake, it has been greatly revised in Japanese highway bridge codes. It was secured a large gap size of the girder for the collision of girders by the Level 2 Earthquake Ground Motion of the seismic design. However, if a large gap size of the girder is adopted, the expansion joint have to be largely changed. Furthermore, the construction costs and the seismic reinforcement costs will be increased. It was considered that the gap reduction allowing the collision of girders, as a premise of preventing the collapse of the bridge, was one of the seismic reinforcement method in order to decease the construction costs and the seismic reinforcement costs. In addition, it is necessary that damage of the girder end and the pier bottom is decreased by attaching rubber shock absorber to the end of girder. In order to reduce gap size between girders, it is necessary that the resistance characteristics of the abutment due to the collision of girders and the dynamic response characteristics due to the damping at the bottom of pier are grasped. Although many studies on the collision phenomenon of bridge girders have been published, the effects of cost on seismic reinforcement allowing the collision of PC bridge girders have not been sufficiently considered yet. In this study, the resistance characteristics of the abutment due to the collision of girders and the dynamic response characteristics due to the damping at the bottom of pier will be verified by carrying out dynamic response analysis that the 3-dimensional finite element model (3D-FEM) of the PC bridge was built. In addition, the effects of cost on the proposed seismic reinforcement allowing the collision of concrete bridge girders will be considered. From the comparison of the total cost on both the current method and the proposed one, it will be confirmed that the proposed seismic reinforcement method is very effective.
\end{abstract}

Keywords: Seismic Response Reduction, Isolation Rubber, Collision, Wing Wall, Seismic Reinforcement Method

\section{Introduction}

A large number of bridges were damaged during unexpectedly severe earthquakes, such as 1995 Kobe strong earthquake and 2011 Tohoku strong earthquake. Damage of these existing bridges primarily occurred in reinforced concrete substructures, abutment, at base of steel piers, in girders collapsed by insufficient support length and bearing failure. Through the damage analysis, the most common problems observed for collapsed of abutments were damage caused by high stress on the surface of abutment and collision between two adjacent girders and between girder and abutment. Therefore, a new type of abutment with a better seismic performance is required to develop. Seismic response investigation of reinforced concrete abutment is very important in term of the ability to resist in severe earthquake. Furthermore, a proper material model of reinforced concrete should be capable in representing the behavior of materials in finite element packages.

In the seismic design specified by Japanese Specifications 
of Highway Bridges (JSHB), a large gap size between two adjacent girders or the girder and abutment has recommended to be constructed in the concrete girder bridge with multi-spans in order to prevent the collision, when it is subjected to Level 2 Earthquake Ground Motion of the seismic design [1]. However, the adoption of large gap into PC bridge will increase the construction and seismic reinforcement costs since relatively large expansion joints have to be used. It has been suggested that allowing the girder collision at the abutment by restricting the girder bridges displacement, the size of expansion joints can be reduced. These conditions are able to reduce the seismic design and seismic reinforcement cost. The authors investigated the Imokawa Bridge that sustained noticeable damage as a result of girder-abutment collision during the 2005 Niigata-Chuetsu Earthquake [2]. According to this study, one such example of damaged to the parapet wall of abutment and movable bearing due to collision are shown in Figure 1 and Figure 2. From these two Figures, it can be seen that the main girder end and front face of parapet wall of the bridge suffered cracks and spalling caused by a collision. The impact force between parapet wall and deck was also large. Desy Setyowulan et al. investigated the possibility of earthquake response reduction based on damage assessment of abutments and bridge piers during collisions [3-5]. The wing type of the abutment was considered to be a parallel type designed with a two-sided fixed version. A hybrid reduction method of seismic response including girder impact and seismic isolation rubber was examined. Furthermore, as one measure to reduce the seismic response without changing the existing bearing conditions, the effectiveness of the seismic response reduction method by seismic isolation of the pier bottom was examined in addition to the girder collision. According to this analysis, it was found that the effectiveness of the hybrid reduction method of the seismic response can be confirmed depending on the input earthquake motion by considering the beam end collision and the seismic isolation pier. Lilya Susanti et al. were conducted an experimental investigation and behavior of reinforced concrete parapet wall of abutment under collision [6]. The collision load from superstructure was idealized by incremental static horizontal load through its rupture. The influence of the collision effect on parapet wall of abutment and reinforcement was analyzed. However, the study on the effects of cost performance was not yet considered.

In this study, Level 2 Earthquake Ground Motion of the seismic design is simulated and the effectiveness of the hybrid seismic response reduction method is discussed. The wing type of the abutment is chosen the parallel type designed with the two-sided fixed condition. In addition, a cost-effectiveness survey of the wing type of the abutment is investigated.

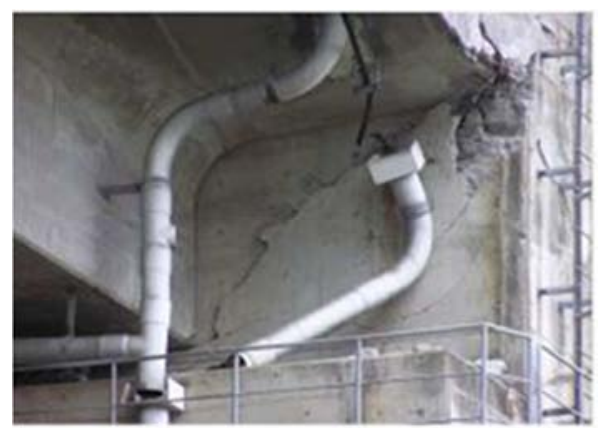

Figure 1. Damage of parapet wall of Imokawa Bridge due to collision.

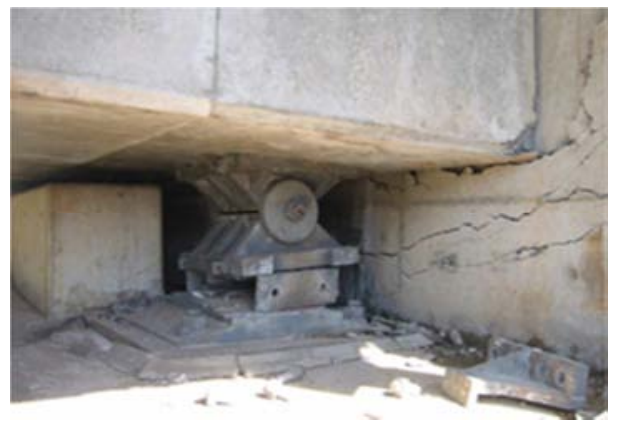

Figure 2. Damage of movable bearing of Imokawa Bridge due to collision.

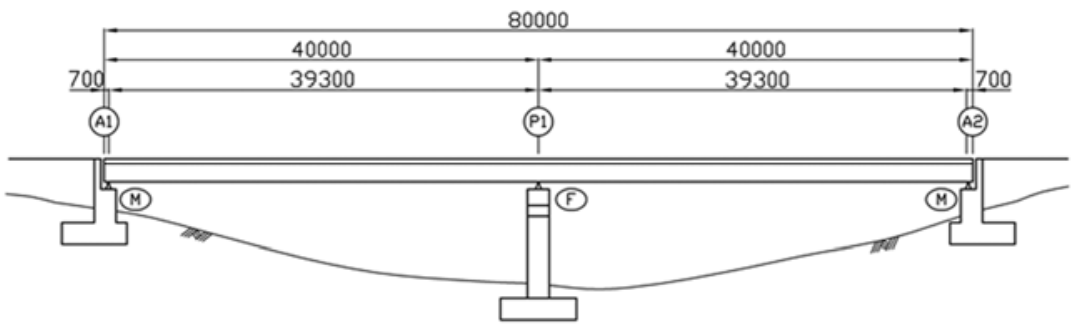

(a) Side view of the PC girder bridge.

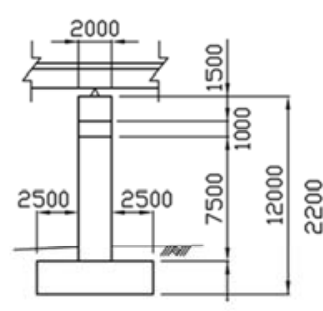

(b) Box cross-section of PC girder

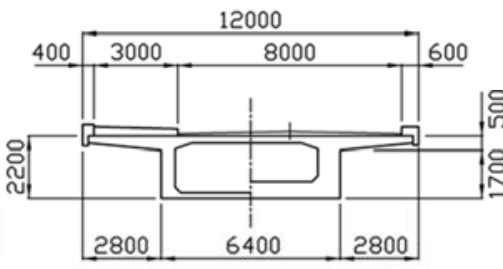

(c) Front view of $\mathrm{P} 1$ pier

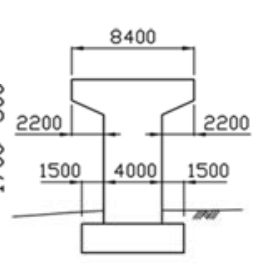

(d) Side view of $\mathrm{Pl}$ pier

Figure 3. The target PC girder bridge (unit: $\mathrm{mm}$ ). 


\section{Outline of Analytical Method}

In advance of the seismic response analysis, the eigenvalue analysis was carried out in order to check the validity of the modelling method, natural frequency and vibration modes of the target bridge. The seismic response analysis using a commercial FEM program ABAQUS was conducted by changing the gap size under Level 2 Earthquake Ground Motion [7]. Parametric study of PC girder bridges taking into account the effect of the wing wall and seismic isolation rubber at the bottom of pier were investigated.

\subsection{Analytical Model}

The real medium size PC girder bridge was chosen as the target bridge in order to evaluate the damage and to grasp the dynamic behavior during earthquake load. The structural profiles of this bridge are composed of two span PC box girder P1 pier with fixed support, and A1 and A2 abutments with movable supports as shown in Figure 3(a). Figure 3(b) shows the $2.2 \mathrm{~m}$ height and $12.0 \mathrm{~m}$ width of box cross-section of PC girder, Figures 3(c) and 3(d) show the side and front views of the P1 pier, respectively. Two abutments with general inverse $\mathrm{T}$ type and a pier of the substructure were made of the reinforced concrete (RC). The foundation of the PC girder bridge was constructed by the direct foundation and was classified Type I ground.

Figure 4(a) shows a 3D analytical FEM model with PC girder, $\mathrm{P} 1$ pier and two abutments. Though the combinations based on various supporting conditions are assumable, the basic analytical model consisting of P1 pier with fixed support and two abutments with movable support is called Model-1. For this basic model, however, the effect of the super-structural inertial force on the bottom of P1 pier was very large. Then, in order to reduce the inertial force and energy absorption due to a strong earthquake, the analytical model with the isolated pier with seismic isolation rubber

is proposed as Model-2. For analytical model, the PC girder and the P1 pier were modelled by shell elements and beam elements including the reinforcement, respectively. The abutment was used solid elements for concrete parts and truss elements for reinforcing bars, respectively. Figure 4(b) shows the FEM model and structural profile of the abutment. The rotation angle was calculated by setting the plastic hinge length at the bottom of pier in Model-1 and considering the axial rebar and lateral hoop ties. The bi-linear stress-strain curve of reinforcement material as shown in Figure 4(c) was adopted for a yield strain, $\varepsilon_{\mathrm{y}}=0.00173$, yield stress, $\sigma_{\mathrm{y}}=345.0$ Mpa, Young's modulus, E=206.0 Gpa and strain hardening modulus, $\mathrm{E}_{2}=\mathrm{E} / 100 \mathrm{Gpa}$. The concrete material with stress-strain multi-curve as shown in Figure 4(d) was used by a maximum compression strain, $\varepsilon_{\mathrm{cc}}=0.00347$, limited compression strain, $\varepsilon_{\mathrm{ccl}}=0.00563$, compression stress, $\sigma_{\mathrm{cc}}=29.4 \mathrm{Mpa}$ and tension stress, $\sigma_{\mathrm{bc}}=\sigma_{\mathrm{cc}} / 100$, respectively. The density of each material was adopted for concrete, $\gamma_{\mathrm{c}}=2450.0 \mathrm{kgf} / \mathrm{m}^{3}$ and reinforcement, $\gamma_{\mathrm{s}}=7850.0 \mathrm{kgf} / \mathrm{m}^{3}$ in the analysis. Material properties of the analytical model were shown in Table 1.

Table 1. Material properties of analytical model.

\begin{tabular}{lll}
\hline Material Properties & Concrete & Rebar \\
\hline Young's modulus $(\mathrm{GPa})$ & 20.60 & 206.00 \\
Poisson's ratio & 0.20 & 0.30 \\
Density $\left(\mathrm{kgf} / \mathrm{m}^{3}\right)$ & 2450.00 & 7850.00 \\
Compressive strength $(\mathrm{MPa})$ & 29.40 & 294.00 (Yield stress ) \\
\hline
\end{tabular}

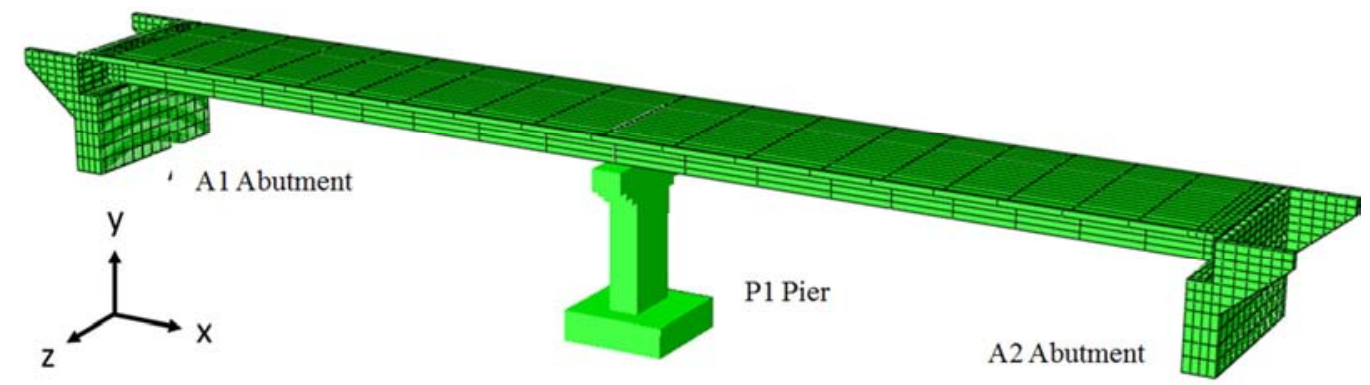

(a) 3D-FEM analytical model with abutment

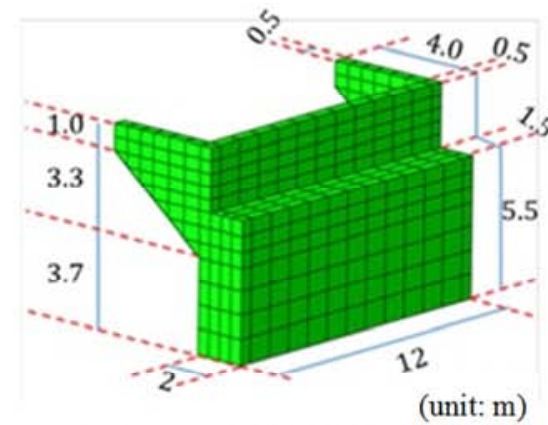

(b) Abutment FEM model

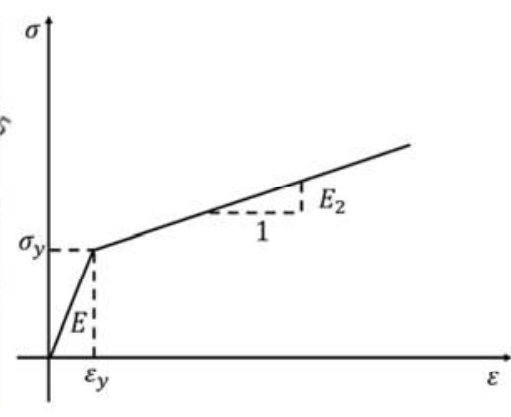

(c) Stress-strain curve of reinforcement

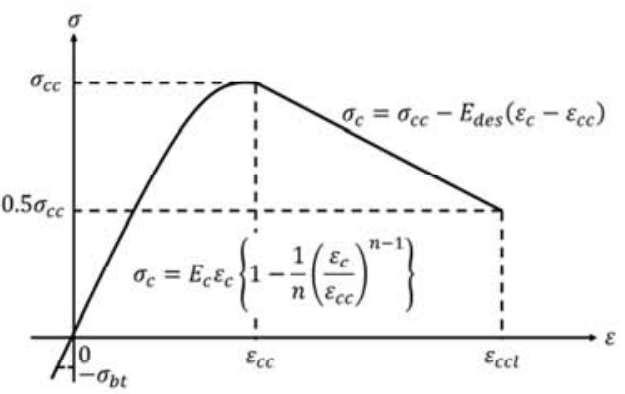

(d) Stress-strain curve of concrete

Figure 4. FEM analytical model and stress-strain curve of materials. 


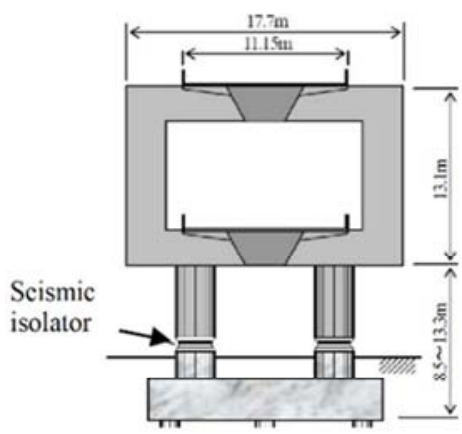

(a) Example of isolated pier [8]

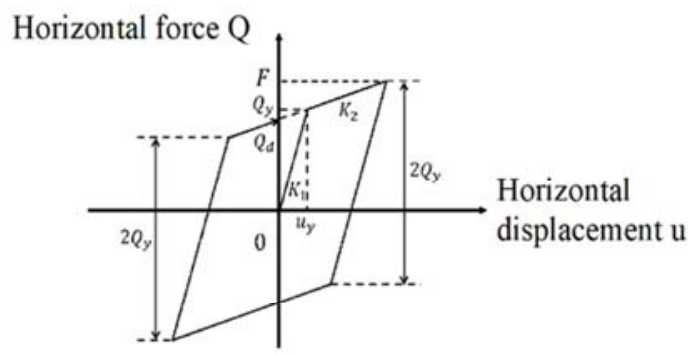

(b) Restoring force-displacement curve of seismic isolation rubber

Figure 5. Modeling of isolated pier.

\subsection{Modelling of the Isolated Pier}

By using the isolated pier with the seismic isolation rubber at the bottom of pier as shown in Figure 5(a), Otsuka et al. clarified that this seismic isolation reduces seismic response [8]. Focusing on the effect of using seismic isolation rubber at the bottom of $\mathrm{P} 1$ pier, the effect of reducing the seismic response of the analytical model was examined.

The restoring force characteristic of seismic isolation rubber used the laminated rubber with lead plugs was assumed the bi-linear curve as shown in Figure 5(b) [9]. The seismic isolation rubber has a bi-linear model with the primary rigidity $K_{1}$ and the secondary rigidity $K_{2}$, respectively. These $K_{1}$ and $K_{2}$ rigidities were calculated by the following formula:

$$
\begin{aligned}
& K_{1}=6.5 K_{2} \\
& K_{2}=\frac{F-Q_{d}}{u B_{e}}
\end{aligned}
$$

where $F$ is the horizontal force $(\mathrm{N})$ in the shear design strain, $Q_{d}$ is the yield load of the seismic isolation rubber, $u B_{e}$ is the effective displacement of the seismic isolation rubber. In this study, the rigidity of the seismic isolation rubber was adopted as $K_{l}=3.45 \times 10^{4} \mathrm{kN} / \mathrm{m}, K_{2}=0.38 \times 10^{4} \mathrm{kN} / \mathrm{m}$ and $Q_{d}=1.42 \times 10^{3}$ $\mathrm{kN}$, respectively.

\subsection{Index of Damage Evaluation Level}

The damage evaluation levels at the bottom of P1 pier were introduced by the experimental results by the quasi-static cyclic loading using actual scale RC bridge piers with rectangular cross sections [10]. Table 2 represents the state of crack and failure of RC bridge pier and damage degree such as crack, yield and ultimate states of test pieces corresponding to the horizontal displacement at $\delta=2 \delta_{\mathrm{y}}, 5 \delta_{\mathrm{y}}$ and $7 \delta_{\mathrm{y}}\left(\delta_{\mathrm{y}}\right.$ : yield displacement) obtained from the experimental results of quasi-static cyclic loading.

Table 2. State of crack and failure on actual RC bridge pier from quasi-static cyclic loading experiments [10].

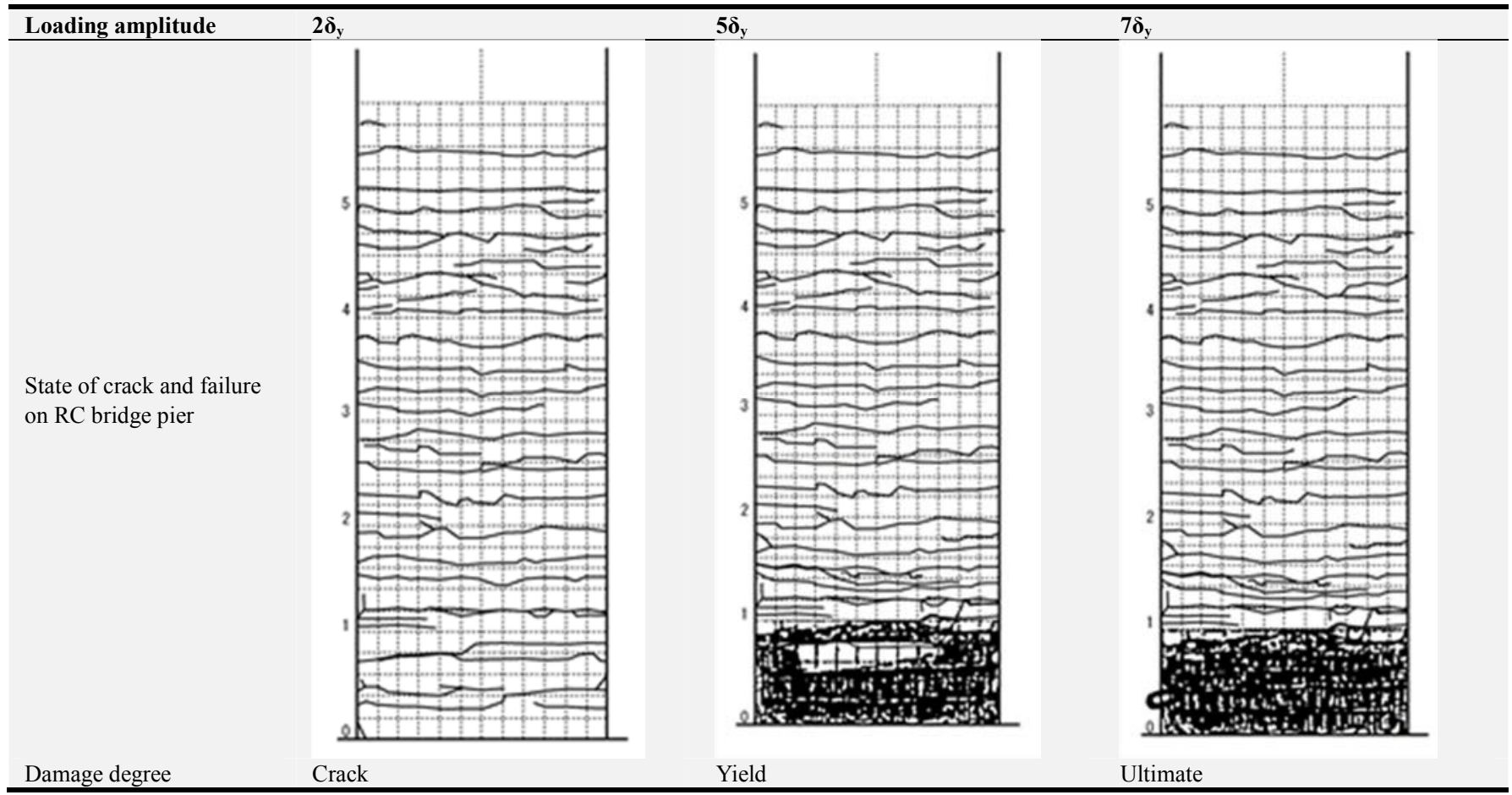


Table 3. Damage evaluation level at the bottom of RC bridge pier

\begin{tabular}{lll}
\hline Response of rotation angle (rad) & Damage level & $\begin{array}{l}\text { Damage } \\
\text { degree }\end{array}$ \\
\hline $0<\theta \leq 3.0 \times 10^{-3}\left(0<\theta \leq 2 \delta_{\mathrm{y}}\right)$ & $\mathrm{A}$ & slight \\
$3.0 \times 10^{-3}<\theta \leq 7.0 \times 10^{-3}\left(2 \delta_{\mathrm{y}}<\theta \leq 5 \delta_{\mathrm{y}}\right)$ & $\mathrm{B}$ & \\
$7.0 \times 10^{-3}<\theta \leq 10.0 \times 10^{-3}\left(5 \delta_{\mathrm{y}}<\theta \leq 7 \delta_{\mathrm{y}}\right)$ & $\mathrm{C}$ & \\
$\theta>10.0 \times 10^{-3}\left(\theta>7 \delta_{\mathrm{y}}\right)$ & $\mathrm{D}$ & heavy \\
\hline
\end{tabular}

From these results, the damage evaluation level of near at the bottom of RC bridge pier was defined as shown in Table 3. The damage level varied such as from slight damage (damage level A) to heavy damage (damage level D) in proportion to the maximum response rotation angle at the bottom of $\mathrm{RC}$ bridge pier.

\subsection{Modelling of the Isolated Pier}

The eigenvalue analysis was carried out in order to investigate the effect of seismic isolation rubber on the natural periods of the analytical model. The natural periods and the effective mass ratio of each predominant mode were investigated in order to understand the fundamental dynamic characteristics of the PC girder bridge. The maximum effective mass ratios in $\mathrm{X}, \mathrm{Y}$ and $\mathrm{Z}$ directions imply the order of the predominant natural period.

\subsection{Input Ground Motion and Analysis Parameters}

Two types of Level 2 Earthquake Ground Motion provided by the JSHB were used in dynamic response analysis [1]. Type I Earthquake Ground Motion (Plate boundary type earthquake with a large magnitude) and Type II Earthquake Ground Motion (Inland direct strike type earthquake) were specified for Level 2 Earthquake Ground Motion of the seismic design.

The input six JSHB seismic waves of Type I and Type II are illustrated in Table 4 and Figure 6. The forced displacement obtained by integrating the acceleration instead of the ground motions have applied in longitudinal direction of the analytical model. The gap size in existing girder bridges is determined in consideration of the amount of the displacement during an earthquake and the temperature change. The seismic response analysis was carried out by changing the gap size from $10 \mathrm{~cm}$ to $50 \mathrm{~cm}$ at girder end under earthquake ground motion.

\section{Results and Discussion}

\subsection{Results of Eigenvalue Analysis}

As the results of the eigenvalue analysis for Model-1 and Model-2, the natural frequency $f$ and the effective mass ratios are summarized in Table 5, and dominant vibration modes are shown in Figure 7(a) and 7(b), respectively. The gap size for Model-1 and Model-2 was fixed at $10 \mathrm{~cm}$ in eigenvalue analysis because the difference of the vibration mode and the natural frequency by changing the gap size from $10 \mathrm{~cm}$ to 50 $\mathrm{cm}$ was so small.

Table 4. Earthquake acceleration waveform list

\begin{tabular}{llll}
\hline Level / Type & Earthquake name & Nickname & Abbreviation \\
\hline \multirow{2}{*}{ II / I } & Tokachi-oki Earthquake 2003 & Type I- & L2T1G1-1 \\
& Northeastern Pacific Ocean off the Coast Earthquake FY 2011 & Type I-2 & L2T1G1-2 \\
& & Type I- 3 & L2T1G1-3 \\
II /II & Hyogo-ken Nanbu Earthquake 1995 & Type II - 1 & L2T2G1-1 \\
& & Type II - 2 & L2T2G1-2 \\
\hline
\end{tabular}

The maximum effective mass ratios obtained in $\mathrm{X}, \mathrm{Y}$ and $\mathrm{Z}$ directions for both Models were $1^{\text {th }}, 4^{\text {th }}$ and $3^{\text {th }}$ of the dominant natural period, respectively. The natural frequency of $1^{\text {th }}$ period was greatly improved from $1.33 \mathrm{~Hz}$ in Model- 1 to 0.54 $\mathrm{Hz}$ in Model-2. That is, it was found that the dominant natural frequency for Model-2 installed the seismic isolation rubber at the base of $\mathrm{P} 1$ pier was reduced by $59 \%$. From the results of eigenvalue analysis, the using the isolated pier with the seismic isolation rubber at the bottom of pier were shown the possibility of the reduction effect of the seismic response.

\subsection{Results of Dynamic Response Analysis}

Figure 8 shows the results of the response of rotation angle at the bottom of $\mathrm{P} 1$ pier in Model-1 by changing the gap size from $10 \mathrm{~cm}$ to $50 \mathrm{~cm}$. From this Figure, it could be seen that the maximum response of rotation angles for model with more than the gap size $20 \mathrm{~cm}$ except Type I-1 wave were exceeded largely the damage level $\mathrm{D}$. The damage level of $\mathrm{P} 1$ pier in Model-1 was comparatively large damage level C or D. That is, it was recognized that the damage degree depending on the gap size was getting small. Since damage to the pier bottom increases after the gap size $20 \mathrm{~cm}$ or more, the PC girder is displaced significantly even if a large gap size is secured to avoid a collision, which is a heavy burden on the base of pier. It is important to propose appropriate methods to reduce damage level at the bottom of P1 pier and to minimize abutment damage.

Figure 9 shows the comparison results of the response of rotation angle at the bottom of P1 pier for Model-1 and Model-2 input Type I-2 and Type II-1 waves.

The maximum response of rotation angle at the bottom of P1 pier for Model-2 with the gap size $50 \mathrm{~cm}$ input Type II-1 wave was so small $\mathrm{rad}\left(1.10 \times 10^{-3}\right)$ and the degree of damage of $\mathrm{P} 1$ pier was almost slight (damage level A). 
Table 5. Eigenvalue analytical results for Model-1 and Model-2

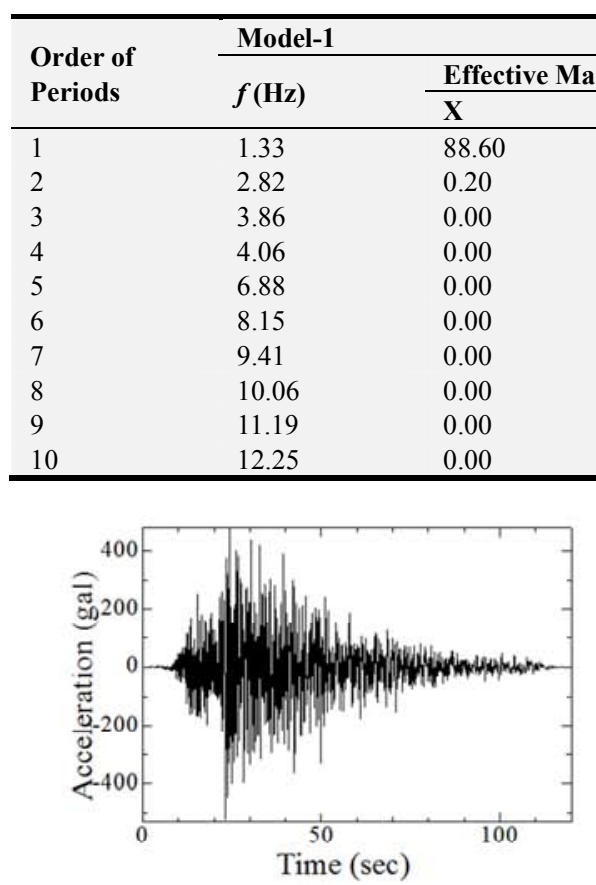

(a) Type I-1 wave

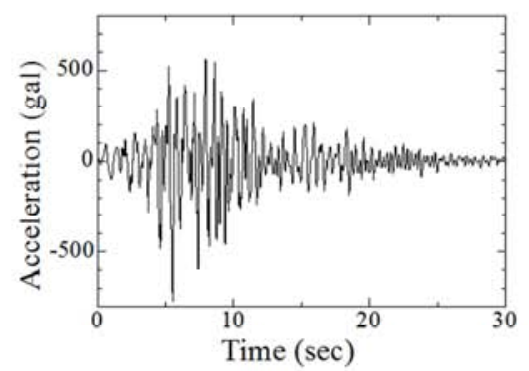

(d) Type II-1 wave

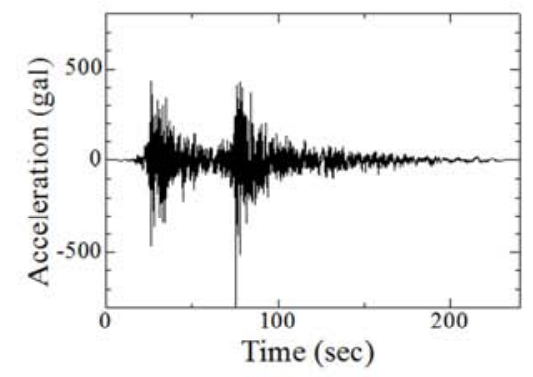

(b) Type I-2 wave

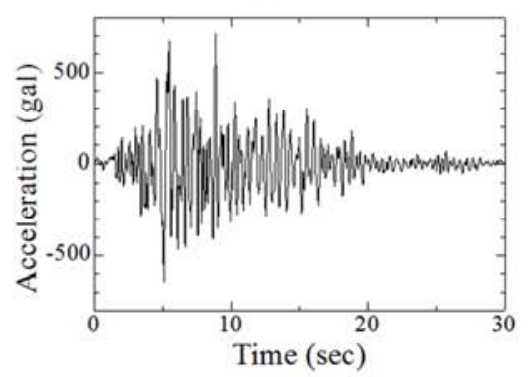

(e) Type II-2 wave

\begin{tabular}{llll} 
Model-2 & \multicolumn{4}{l}{} \\
\cline { 2 - 4 } $\boldsymbol{f}(\mathbf{H z})$ & $\mathbf{X}$ & $\mathbf{Y}$ & $\mathbf{Z}$ \\
\hline 0.54 & 89.10 & 0.00 & 0.00 \\
2.81 & 0.00 & 0.00 & 0.00 \\
3.77 & 0.00 & 83.50 & 1.00 \\
4.11 & 0.00 & 1.00 & 75.10 \\
6.89 & 0.00 & 0.00 & 0.00 \\
7.77 & 0.00 & 0.00 & 6.50 \\
9.02 & 0.00 & 4.50 & 0.00 \\
9.41 & 0.00 & 0.00 & 0.00 \\
10.02 & 0.00 & 0.00 & 0.00 \\
11.60 & 0.00 & 0.00 & 0.00 \\
\hline
\end{tabular}

Figure 6. Input JSHB acceleration waves of Level 2 Earthquake Ground Motion [1]

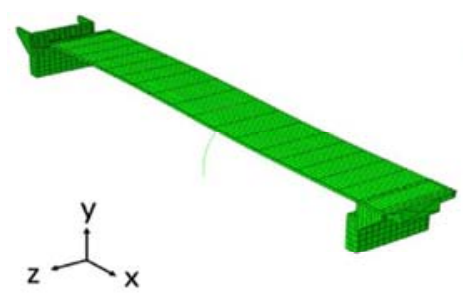

(1) $1^{\text {th }}$ mode (X-direction)

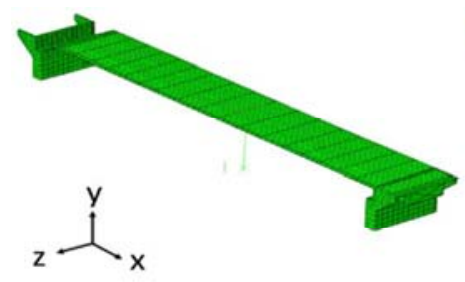

(1) $1^{\text {th }}$ mode (X-direction)

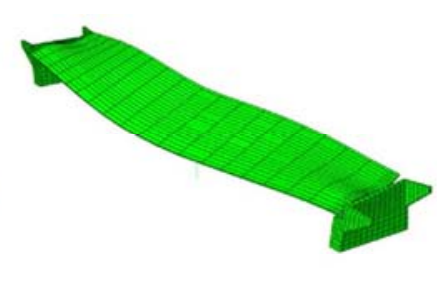

(2) $3^{\text {th }}$ mode (Z-direction)

(a) Model-1

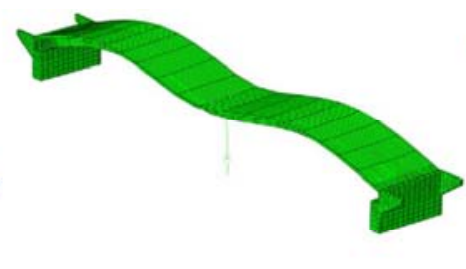

(2) $3^{\text {th }}$ mode (Z-direction)

(b) Model-2

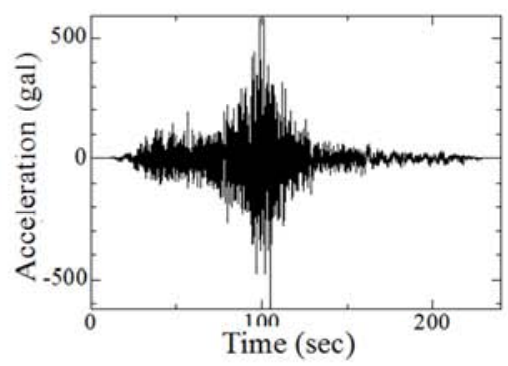

(c) Type I-3 wave

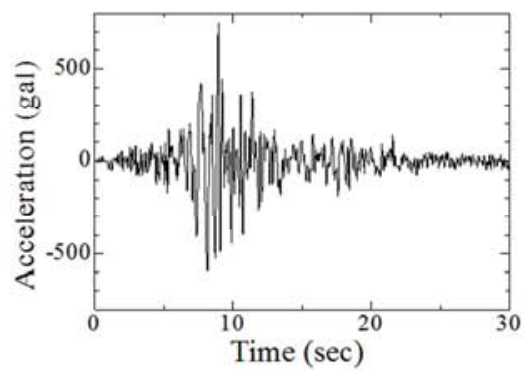

(f) Type II-3 wave

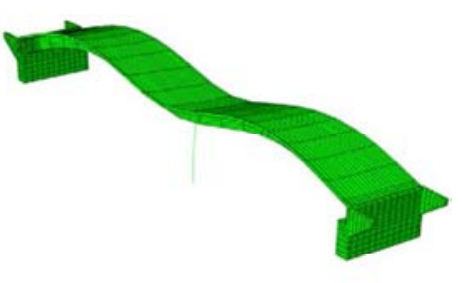

(3) $4^{\text {th }}$ mode (Y-direction)

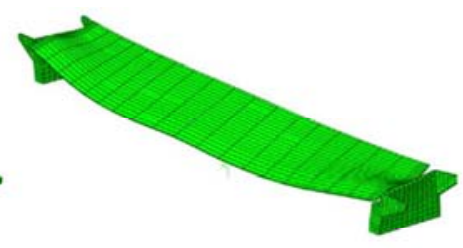

(3) $4^{\text {th }}$ mode (Y-direction)

Figure 7. Dominant vibration modes for Model-1 and Model-2. 

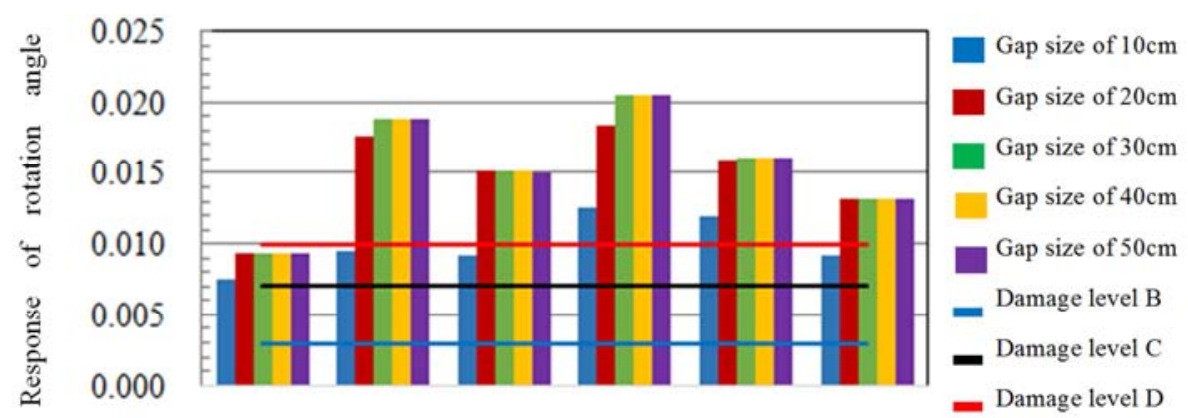

Type I-1 Type I-2 Type I-3 Type II-1 Type II-2 Type II-3

Figure 8. Response of rotation angle at the bottom of $P 1$ pier.

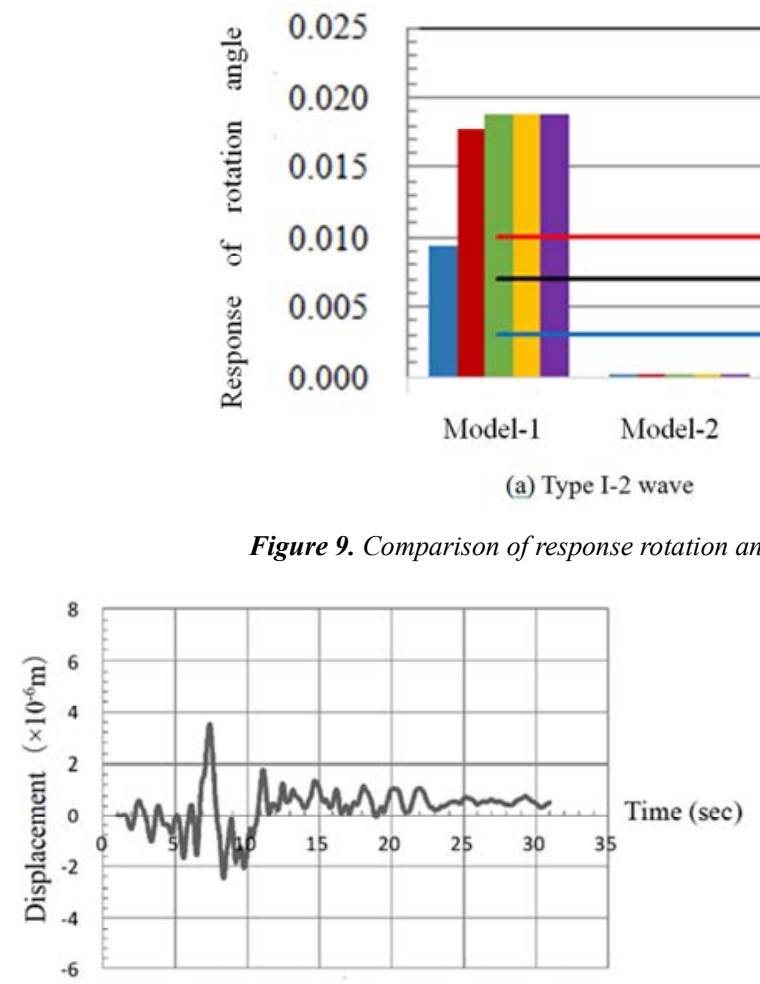

(a) Type I-2 wave

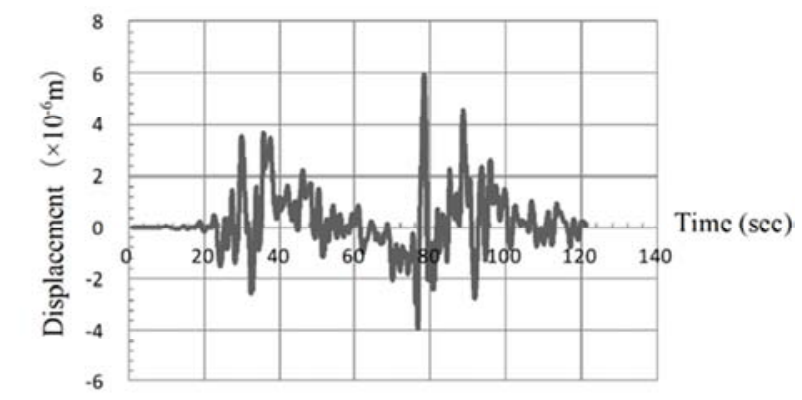

(b) Type II-1 wave

Figure 10. Time histories of response displacement for Model-2 with the gap size of $50 \mathrm{~cm}$.

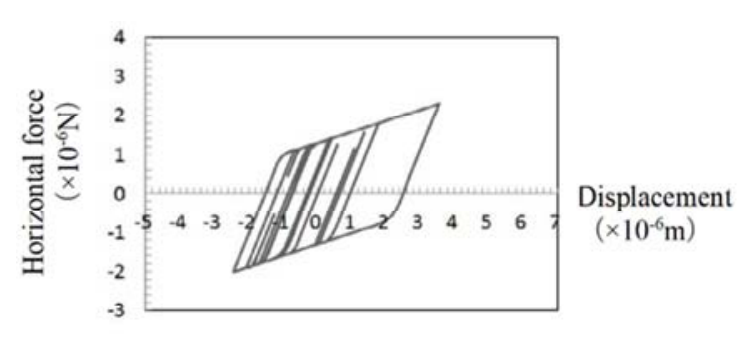

(a) Type I-2 wave

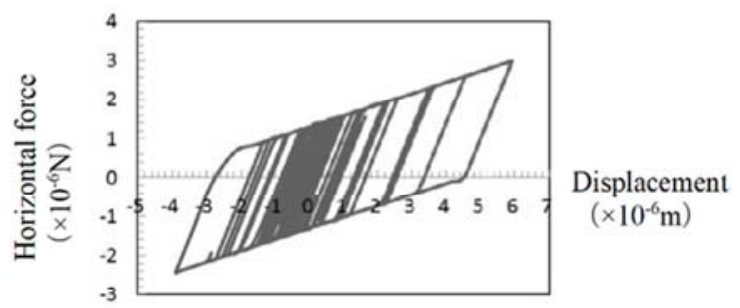

(b) Type II-1 wave

Figure 11. Relationship between horizontal force and displacement of seismic isolation rubber for Model-2 with the gap size of $50 \mathrm{~cm}$.

The damage of Model-2 with the isolated pier in comparison with that of Model-1 with the general pier was all slight in not relation to the gap size input Type I-2 and Type II-1 waves. By installing seismic isolation rubber at the bottom of P1 pier, the load on the base of the pier can be greatly reduced by seismic isolation. That is, the validity of the seismic isolation rubber was recognized. Based on these analytical results, it was found that there is a possibility of controlling of the allowance a certain amount of girder collision and a slight damage of the abutment and the pier bottom by using a girder bridge which consists the pier with seismic isolation rubber and the girder with the gap size $20 \mathrm{~cm}$ 
- $30 \mathrm{~cm}$. Figure 10 and Figure 11 show time histories of response displacement and the relationship between horizontal force of seismic isolation rubber and corresponding to displacement for Model-2 with the gap size $50 \mathrm{~cm}$ input Type I-2 and Type II-1waves, respectively. From these Figures, the maximum horizontal displacements of seismic isolation rubber were $3.54 \times 10^{-6} \mathrm{~m}$ for Type I-2 wave and $5.93 \times 10^{-6} \mathrm{~m}$ for Type II-1 wave, respectively. The response displacement was smaller than the size of the girder, and it was confirmed that the seismic response was reduced largely by installed the seismic isolation rubber in this study.

\subsection{Proposed the New Seismic Reinforcement Method}

From the results of dynamic response analysis, it was found that the response of rotation angle at the bottom of $\mathrm{P} 1$ pier was reduced when the gap size was small. Therefore, the effectivity of the new method of seismic reinforcement with the allowed collision of girder with a small gap size was investigated in terms of the seismic reinforcement cost.

Figure 12(a) shows the comparison of the current method and the proposed new one for seismic reinforcement design. The current method of seismic reinforcement was a method that was not allowed to collide girder. The current seismic reinforcement design method has the following features; 1)
Adoption of the large gap size and no allowing collision at end girder, 2) Replacement the existing bearing with the rubber one, 3) Seismic reinforcement in consideration of toughness for pier, 4) Reconstruction of the parapet at abutment, 5) Replacement the existing expansion joint with a large one.

On the other hand, Figure 12(b) shows the cost reduction effect of the proposed new method for seismic reinforcement design. The proposed seismic reinforcement design method has the following characteristics; 1) Allowing collision at end girder and no change the gap size, 2) Set up the wing walls at abutment to improve the resistance, 3) Install the isolation rubber with LRB (Lead Rubber Bearing) at the bottom of bridge pier, 4) Widening the bridge seat of abutment, 5) Mounting shock absorber devices at the end of girder, 6) No change the parapet of abutment, the existing bearing and the expansion joint, 7) Connecting the girder with the abutment by PC cables. The last item is most important suggestions in the proposed method. The approximate costs of seismic reinforcement were calculated both the current method and the proposed one and the results were shown in Table 6 and Figure 13. From the comparison of the total cost of both methods, it was recognized that $57 \%$ reduction of the total cost was seen and the effectivity of the proposed new method for seismic reinforcement design was large.

Table 6. Comparison of approximate seismic reinforcement cost (thousand yen)

\begin{tabular}{|c|c|c|c|c|}
\hline Seismic reinforcement design & Current method & & Proposed new method & \\
\hline Collision of girder & Not allowing collision & & Allowing collision & \\
\hline Gap size of girder & Large gap size & & Reducing gap size & \\
\hline Bearing & Rubber bearings & 26,200 & Not change & 0 \\
\hline \multirow[t]{2}{*}{ Existing bearing } & Removal & 5,400 & Not change & 0 \\
\hline & Reconstruction of parapets & 8,300 & Not change & 0 \\
\hline \multirow[t]{2}{*}{ Abutment } & Not change & 0 & Set up wing walls & 9,000 \\
\hline & Not change & 0 & Widening of bridge seats & 3,700 \\
\hline Expansion joint & Large expansion joints & 18,900 & Existing expansion joints & 0 \\
\hline Shock absorber device & Not use & 0 & Mounting & 4,800 \\
\hline Seismic isolation rubber & Not use & 0 & Install of LRB (Lead Rubber Bearing) & 12,100 \\
\hline Bridge restrainer device & Not change & 0 & PC cables & 7,900 \\
\hline Total cost of seismic reinforcement design & $(\alpha=1.00)$ & 75,900 & $(\alpha=0.57)$ & 43,200 \\
\hline
\end{tabular}

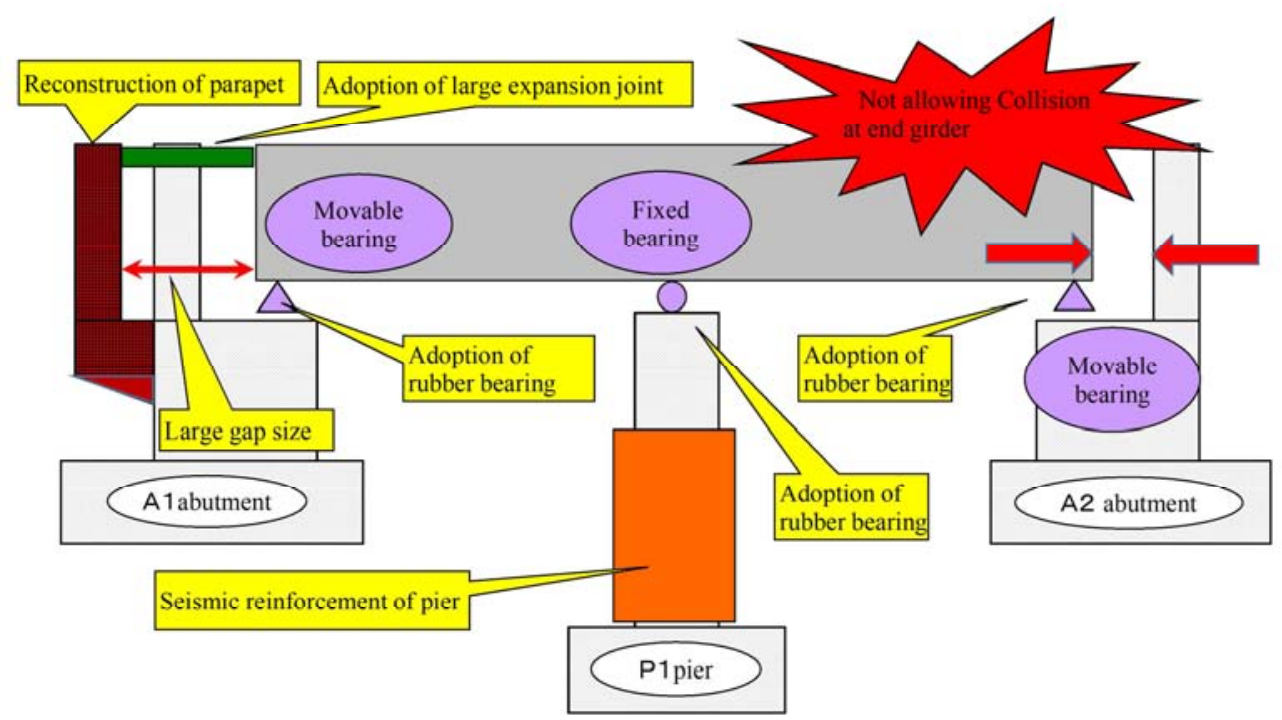

(a) Current method 


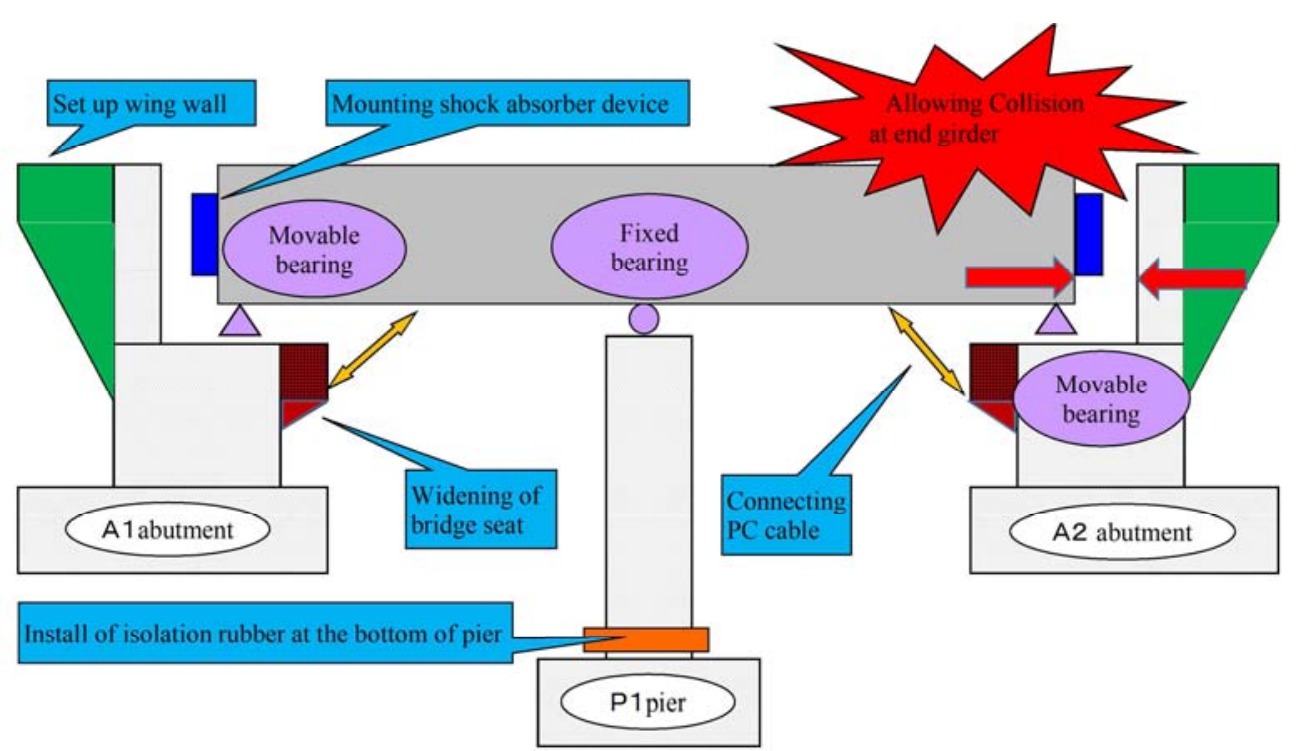

(b) Proposed new method

Figure 12. Seismic reinforcement design.

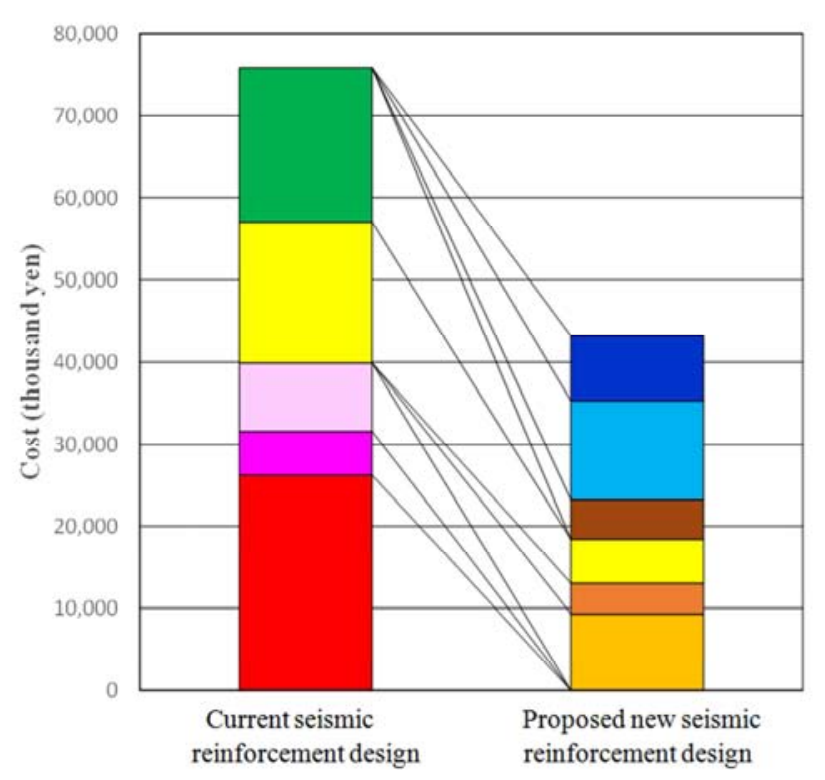

- Bridge restrainer device

- Seismic isolation rubber

n Shock absorber

Expansion joint

Column of pier

Widening of bridge seats at abutment

Wing walls at abutment

Reconstruction of parapets at abutment

- Removal of existing bearing

neplacement of bearing

Figure 13. Comparison of approximate seismic reinforcement cost (thousand yen).

The cost of the current seismic design method is so high due to the replacement of existing bearings with rubber bearings, the use of relatively large expansion joints and the seismic reinforcement of the bridge pier. However, though the cost of set up the wing walls at abutment and of install the isolation rubber with LRB at the bottom of bridge pier were slightly high, the proposed new method can greatly reduce the design cost because the improvement of the resistance characteristics by the set up the abutment wing and the effect of seismic response reduction by the isolation rubber.

\section{Conclusions}

The seismic behavior of PC girder bridge subjected to strong ground motions considering the effect of collision, the pier bottom of seismic isolation rubber and wing wall were investigated. The dynamic response analysis using 3D-FEM. The seismic response analysis was carried out by changing the gap size from $10 \mathrm{~cm}$ to $50 \mathrm{~cm}$ at girder end under six seismic acceleration waves of Level 2 Earthquake Ground Motion. The effects of cost on the proposed seismic reinforcement method allowing the collision between girder and abutment were considered. The main conclusions of this study were summarized as following.

1) From the results of eigenvalue analysis, the using the isolated pier with the seismic isolation rubber at the bottom of P1 pier were shown the possibility of the reduction effect of the seismic response.

2) Based on seismic response analytical results, it was found that there is a possibility of controlling of the allowance a certain amount of girder collision and a slight damage of the abutment and the pier bottom by 
using a girder bridge which consists the pier with seismic isolation rubber and the girder with the gap size $20 \mathrm{~cm}$ $30 \mathrm{~cm}$.

3) As a result of the damage evaluation by numerical analysis for a model (Model-2) that the seismic isolation rubber was installed at the bottom of P1 pier without changing the support conditions, the damage degree to the P1 pier was slight in addition to the damage due to the collision between girder and abutment if the gap size of girder was secured about $20 \mathrm{~cm}-30 \mathrm{~cm}$.

4) The response displacement was smaller than the size of the girder, and it was confirmed that the seismic response was reduced largely by installed the seismic isolation rubber in this study.

5) The approximate costs of seismic reinforcement were calculated both the current method and the proposed one and the results. From the comparison of the total cost of both methods, it was recognized that $57 \%$ reduction of the total cost was seen and the effectivity of the proposed new method for seismic reinforcement design was large.

\section{References}

[1] Japan Road Association. "Specification for Highway Bridges", Part V Seismic Design, Tokyo, Japan, November, 2017. (in Japanese).

[2] Tomohisa Hamamoto, Kenji Kosa, Hironori Abe, Yasuo Inokuma and Yoshifumi Nariyuki. "A study on damage mechanism of a bridge that suffered disaster with the Niigata-ken Chuetsu earthquake", Journal of Structural Engineering, JSCE, Vol. 52A, pp. 349-356, March, 2006. (in Japanese).

[3] Desy Setyowulan, Tomohisa Hamamoto and Toshitaka Yamao. "Elasto-Plastic Behavior of 3-Dimensional Reinforced
Concrete Abutments Considering the Effect the Wing Wall", International Journal of Civil Engineer and Technology, pp. 97-113, November, 2014.

[4] Desy Setyowulan, Keizo Yamamoto, Toshitaka Yamao and Tomohisa Hamamoto. "Dynamic Analysis of Concrete Girder Bridges Under Strong Earthquakes: the Effect of Collision, Base-Isolated Pier and Wing Wall", International Journal of Civil Engineering and Technology, pp. 79-93, April, 2015.

[5] Desy Setyowulan, Toshitaka Yamao, Keizo Yamamoto and Tomohisa Hamamoto. "Investigation of seismic response on girder bridges - the effect of displacement restriction and wing wall types", Procedia - Social and Behavioral Sciences 218, pp. 104-117, May, 2016.

[6] Lilya Susanti, Desy Setyowulan and Ming Narto Wijaya. "An Experimental Investigation on Behavior of RC Parapet Wall of Abutment under Collision", International Journal of Civil Engineering and Technology, 9 (9), pp. 1831-1838, September, 2018.

[7] Dassault Systèmes Simulia Corp. "ABAQUS Analysis User's Manual”, Version 6.11, USA, January, 2011.

[8] Hisanori Otsuka, Shigeyuki Kuriki, Jeung-Geun Park, Yasuyuki Suzuki and Takayuki Tsuchida. "Study on the seismic isolation of high-elevated rigid-frame steel bridge with double deck", Journal of Structural Engineering, JSCE, Vol. 45A, pp. 869-878, March, 1999. (in Japanese).

[9] Tsutomu Usami, Shogo Kiyokawa and Akira Kasai. "Analysis model of seismic isolation bearing in consideration of $\mathrm{P}-\Delta$ effect", Proceedings of the 3rd Symposium on Seismic Design of Bridges based on Design Ultimate Horizontal Strength during an Earthquake, JSCE, pp. 143-150, December, 1999. (in Japanese).

[10] Junichi Hoshikuma, Shigeki Unjoh and Kazuhiro Nagaya. "Spacing effect on inelastic behavior of reinforced concrete columns subjected to cyclic loading", Journal of Structural mechanics and earthquake engineering, JSCE, No. 669 / V-50, pp. 215-232, February, 2001. (in Japanese). 